2 emerald International Journal of Building Pathology and Adaptation

\title{
Sustainable Refurbishment for School Buildings: A Literature Review
}

\begin{tabular}{|r|l|}
\hline Journal: & International Journal of Building Pathology and Adaptation \\
\hline Manuscript ID & IJBPA-01-2018-0009.R1 \\
\hline Manuscript Type: & Original Article \\
\hline Keywords: & $\begin{array}{l}\text { sustainable refurbishment, school buildings, LCA, LCC, BIM, building } \\
\text { refurbishment }\end{array}$ \\
\hline $\begin{array}{l}\text { Note: The following files were submitted by the author for peer review, but cannot be converted to } \\
\text { PDF. You must view these files (e.g. movies) online. }\end{array}$ \\
\hline Figures.vsdx \\
\hline
\end{tabular}




\section{Abstract}

Purposes - Any building refurbishment is challenging and school buildings offer no exception. They are increasingly in need of refurbishment due to their age and evolving teaching and learning. This paper will present an overview of literature on sustainable refurbishment so as to identify key lessons from selected successful refurbishment projects. The review findings are expected to contribute to the development of refurbishment plans in an effective and innovative manner that should extend building's service life, focus on resource efficiency, and comfort their users. It will also contribute to knowledge base of refurbishment and suggest future directions for research.

Design/methodology/approach - The paper has undertaken a literature review on the sustainability assessment of buildings and frameworks for sustainable refurbishment. Besides, the work also provides a review of recent successful refurbishment projects to collect and structure systems experiences which can be adopted in developing a sustainable refurbishment strategy for school buildings.

Findings - Findings include three groups of lessons in terms of reasons, process and barriers in the selected refurbishment projects that assist stakeholders to prepare a suitable refurbishment plan for their school buildings. The potential of 3D scanners and BIM applications in the refurbishment process will also be reviewed in order to develop a proposed framework of 3D scanner vs BIM for the refurbishment process. Recommendations highlight the role of a national strategy as a driving factor for applying the advantages of information technology to enhance optimal solution selection processes to get better and more sustainable results.

Originality/value - The conceptual framework for 3D scanner and BIM applications within sustainable refurbishment for school buildings is currently under researched, and the findings aimed to address such a gap when considering 3D scanners and BIM applications in the refurbishment process.

Keywords: building refurbishment, BIM, LCA, LCC, school buildings 


\section{Introduction}

Built Environment is one of the biggest concerns for sustainable development as the construction sector is one of the main reasons for natural resource depletion, the greenhouse effect, and climate change. For example, the construction industry accounts for $40 \%$ of $\mathrm{CO} 2$ emissions - more than any other sector. And buildings consume $70 \%$ of the electricity load in the US (USGBC, 2005). Therefore, sustainable construction is an inevitable requirement for future sustainable development. In fact, buildings are longlived products, typically designed to last 60 years (Shah, 2012), and many buildings have existed for much longer than the designed lifespan as a consequence of being well maintained and refurbished (Meeus, 2012). According to Meeus \& Shah (2012), in developed countries, $70 \%$ of current building stock will exist in the period 2030 to 2050 and the largest environmental, economic and social impacts of built environment act through these existing buildings rather than new ones. Therefore, sustainable refurbishment is becoming increasingly recognized as an effective solution for the existing buildings to extend their life and meet sustainability standards in the construction industry.

When a building has come to the end of its service life, or failed to perform its expected functions, partial refurbishment and full refurbishment can be alternatives instead of demolition (Ali et al., 2009). Refurbishment means 'to furbish again' and 'furbish' is 'to restore to freshness of appearance or good condition' or 'to polish' (Steven and Shephearrd, 2009). Many researchers state that refurbishment of a building refers to "upgrade, major repairs work, renovations, alterations, conversions, extensions, and modernization of existing building" (Quah, 1988; Ali, Noordin \& Rahmat, 2005). Its aim is to provide "modification and improvements to an existing building in order to bring it up to an acceptable condition" (British Standard 15643-1, 2010). In the refurbishment field, sustainable refurbishment can extend the life of existing buildings, and enable the buildings to have functional adaptations and energy efficiency measures as well which could reduce adverse environmental impacts and the life cycle cost of the buildings (Bhuiyan et al., 2015). It also is believed that it is more advantageous to introduce sustainable refurbishment strategy to public buildings, compared to commercial, industry and residential buildings because their maintenance cost is paid for by national budget and their performance is monitored by the authorities. Although public buildings comprise only $12 \%$ of the total building stock (Herczeg et al., 2014), the benefits of sustainability which are achieved through sustainable refurbishment can be demonstrated by providing reliable information, including energy saving potentials to enhance the use of innovative and energy saving retrofit concepts in public buildings. Then, according to the database, it can develop benchmarking systems for other sectors or the whole industry to meet sustainable construction standards.

Among existing buildings, schools buildings provide, first and foremost, spaces and services for the acquisition of knowledge, and socialization and are essential 
foundations for the forming of good citizens of the future (Trachte and De Herde, 2015). In other words, school buildings can play a role in students' individual development through their high-quality interior and exterior layout which can foster the creation of an atmosphere conducive to learning. However, most school buildings possess old technology with regard to ventilation, thermal fittings, lighting, and acoustic (Trachte and De Herde, 2015). Consequently, these buildings are operating with high water and electricity consumption levels, high $\mathrm{CO} 2$ emissions and uncomfortably poor light and noise considerations. The poor quality of school facilities not only has negative influences on students' performance but also may pose health hazards for students, a most vulnerable group, and our future citizens. Meanwhile, as Orsterreicher \& Geissler (2016) pointed out, learning environments have changed and new teaching methods are emerging, leading to requirements for functional improvements to buildings to adapt to new learning spaces. These issues, therefore, raise an urgent need for proper sustainable refurbishment plans for school buildings - sooner rather than later.

This paper aims (1) at a comprehensive literature review of sustainability assessment and sustainable refurbishment of existing buildings, (2) at comparisons with, and lessons from previous successful sustainable refurbishment projects, and (3) at the identification and discussion of current trends and research gaps in this area that would benefit from the application of advanced technology such as 3D laser scanning and Building Information Modelling. The results of this research are useful for schools' decision makers and researchers involved in the implementation of sustainable refurbishment for school buildings.

\section{Sustainability Assessment of Buildings}

Construction diversity makes it complicated to define sustainability in the industry. Although there is no official standard definition for sustainability in the construction industry (Chong et al., 2009), it can be understood as "how the attributes of the activities, products or services used in construction work, or the use of the construction work, contribute to the maintenance of ecosystem components and functions for future generations" (British Standard 15392, 2008). Addressing sustainability in construction involves the parallel and integrated consideration of three primary aspects: environment, economic and social, about requirements for technical and functional performance of construction work. The International Council for Research and Innovation in Building and Construction (CIB) expected that sustainable construction will lead to healthier built environment and ecological systems, energy conservation, better health and comfort for users, waste reduction, resource saving, better service life prediction, and new technologies, and systems for renovating and retrofitting (Bourdeau, 1999).

The three primary aspects of sustainability in construction have a strong relationship and correlation. For example, technical solutions and systems in the building, such as 
heating, ventilation and the air conditioning system, can affect the economic and environmental impacts of buildings and guidelines on the selection of materials, resulting in the users' comfort. However, the overlapping of the three aspects is common, but the degree of overlap will vary and may lead to a positive impact in one aspect while resulting in an adverse impact on the others (British Standard 15392, 2008). Therefore, how to set priorities for each aspect in a balanced relationship with the others is still a challenge. Sustainability assessment of a building is characterized by complexity (multi-disciplinary knowledge, multi-spatial and time scales), uncertainty (many variables, inadequate information and data availability) and urgency (urgency of actions towards challenges like climate change). It is difficult to use one available method that can address all of these aspects, as shown by the many approaches proposed in different disciplinary areas (Zamagni, 2012).

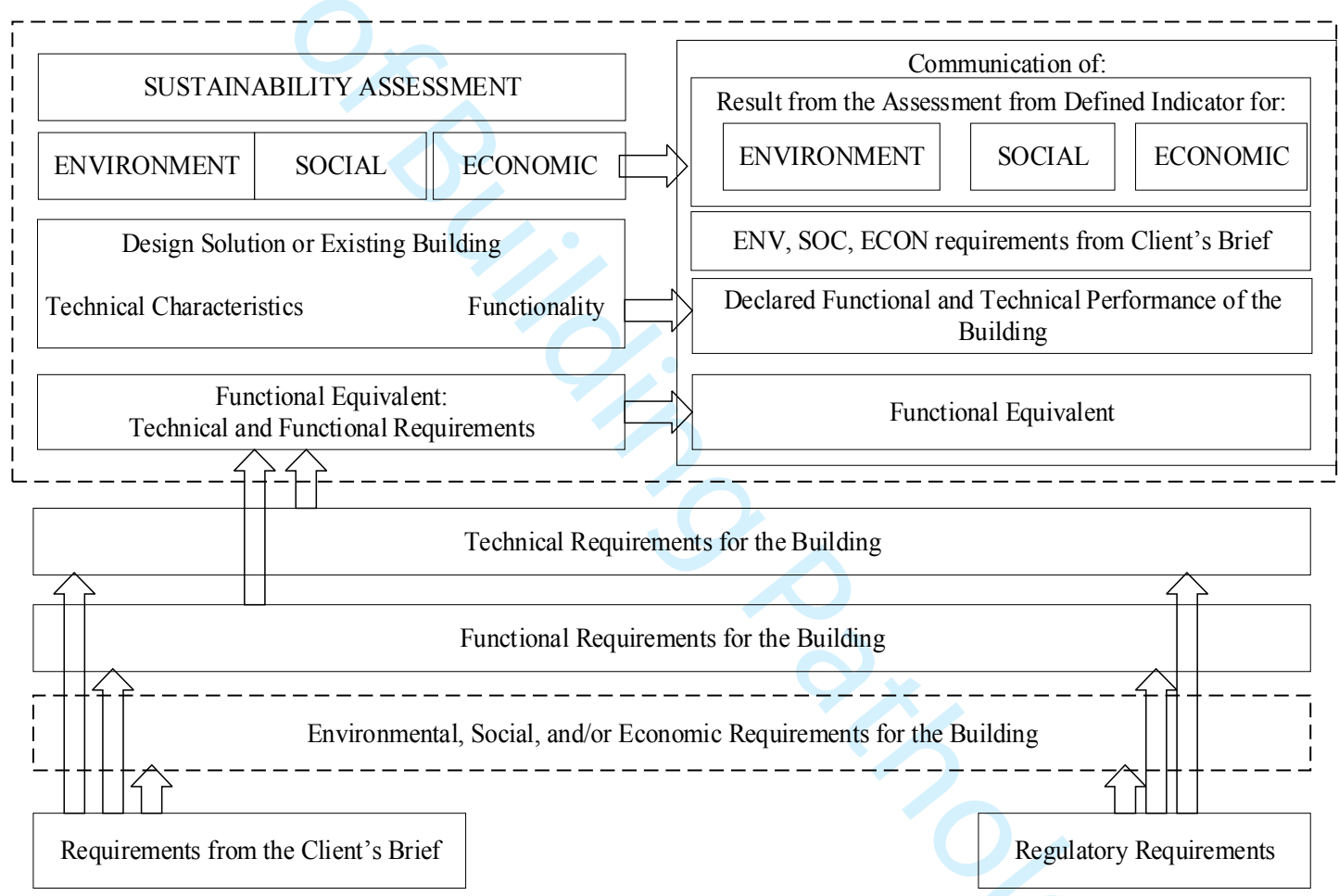

Figure 1: Sustainability Assessment of a Building. Source (BSI, 2015)

As indicated in Figure 1, the results of the assessment of the sustainability performance of a building are required directly from both the Client's concerns and the overall requirements of interested parties. The selection of the relevant system or set of indicators shall reflect the requirements and the proper representation of the assessment goal. The selection is also influenced by the technical and functional requirements within the building life cycle.

There are still gaps on how to integrate sustainability knowledge theories and practices which improve over time. Academics establish the theories and verify the tools for assessing three aspects of SC. However, the practices towards achieving sustainability 
are still very complicated and can sometimes be conflicting (Chong et al., 2009). For example, attempts to reduce wastes on site by fabricating off-site and delivery to site may result in increased energy use from transportation. Enhancing using renewable energy and sustainable materials may reduce energy consumption at the usage stage, but the supply chain of regional materials may yet to be established and could cause some delays in construction, leading to risks in time and cost management. Government strategies and policies of innovation and available technologies are planned to solve the challenges (Vollenbroek, 2002).

Regarding environment assessment, there are various certifications schemes to certify buildings achieved levels of environmental performance. The common rating systems include BRE Environmental Assessment Method (BREEAM- the UK), Leadership Energy Environment Design (LEED- the US) and Green Building Council of Australia (GREENSTAR-Australia, New Zealand). Table 1 presents categories assessed by three schemes as well as the rating of each category as follows:

Table 1: LCA Building Rating System

\begin{tabular}{|c|l|l|l|}
\hline Ranking & \multicolumn{1}{|c|}{ LEED } & \multicolumn{1}{c|}{ BREEAM } & \multicolumn{1}{c|}{ GREENSTAR } \\
\hline 1 & Energy and Atmosphere & Energy & Energy \\
\hline 2 & Sustainable Sites & Health and Well being & Indoor Environmental Quality \\
\hline 3 & $\begin{array}{l}\text { Indoor Environmental } \\
\text { Quality }\end{array}$ & Materials & Materials \\
\hline 4 & Materials and Resources & Management & Emissions \\
\hline 5 & Water Efficiency & Land use and ecology & Water \\
\hline 6 & Innovation in Design & Transport & Management \\
\hline 7 & Regional Priority & Waste & Transport \\
\hline 8 & & Water & Innovations \\
\hline
\end{tabular}

All the three systems address energy is the most weighted issues when assessing environmental sustainability of buildings. Though LEED rates Indoor Environment Quality in ranking 3rd after Sustainable sites, BREEAM and GREENSTAR assess the Indoor Environmental Quality or Health and Well-being as the second important category in the assessment. Both LEED and GREENSTAR encourage construction innovations as they can help to achieve other criteria in the life cycle of buildings.

In terms of economic analysis, cost estimation ranges from a single investment or operational analysis to life-cycle cost (LCC). The LCC aims to evaluate the costeffectiveness of alternative design strategies by considering the construction costs, maintenance cost, operation cost, occupancy cost and end of life cost. The use of LCC 

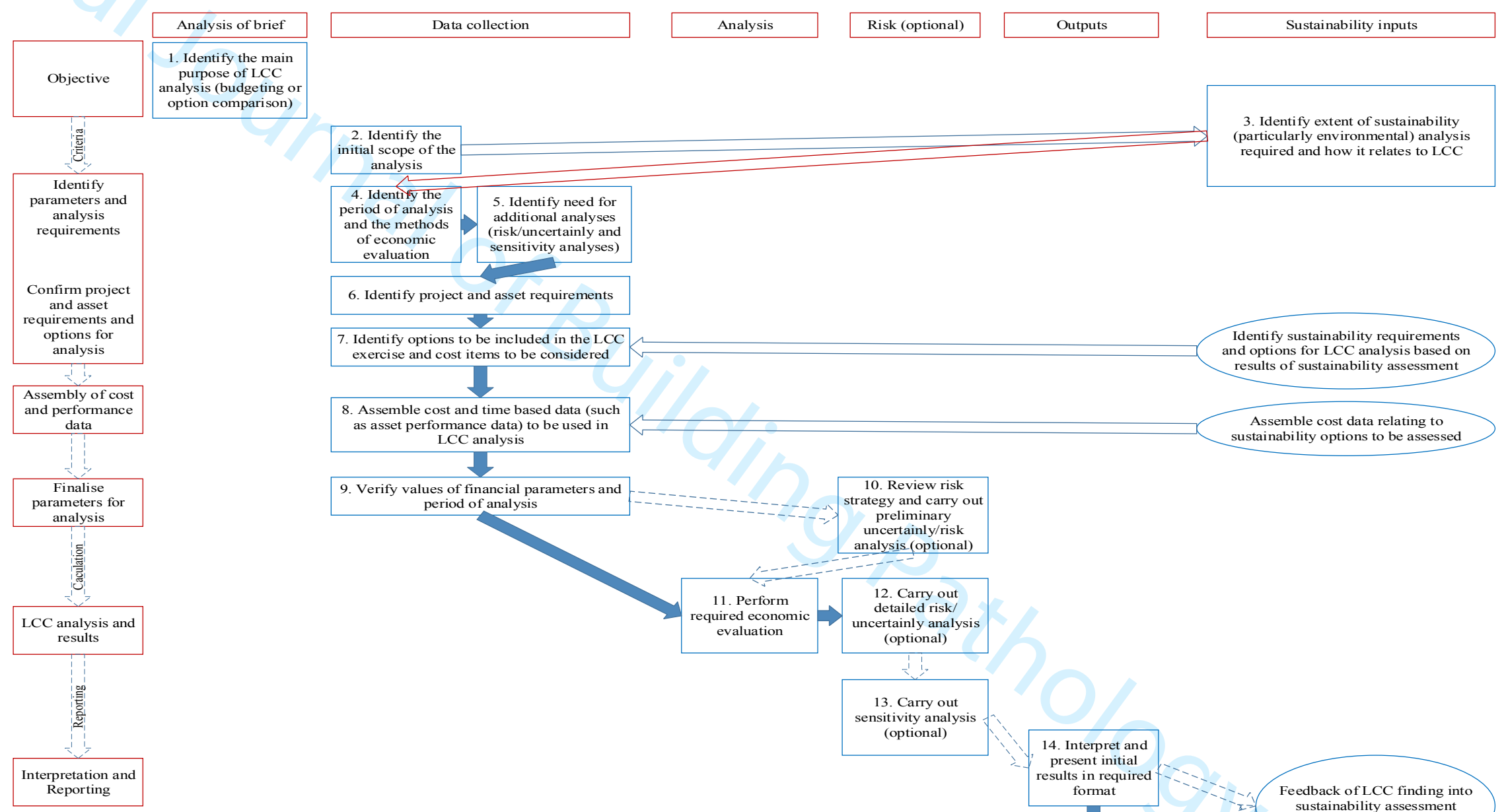

6. Identify project and asset requirements

7. Identify options to be included in the LCC

Identify sustainability requirements

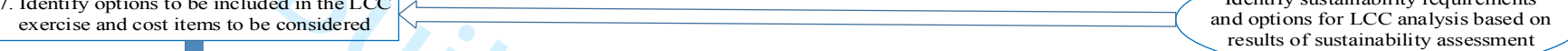
$\checkmark$

8. Assemble cost and iine bas s asset performance data) to be used in LCC analysis tainability assessme

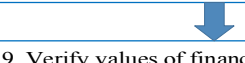

9. Verify values of financial parameters an period of analysis

Assemble cost data relating to
tainability options to be assessed
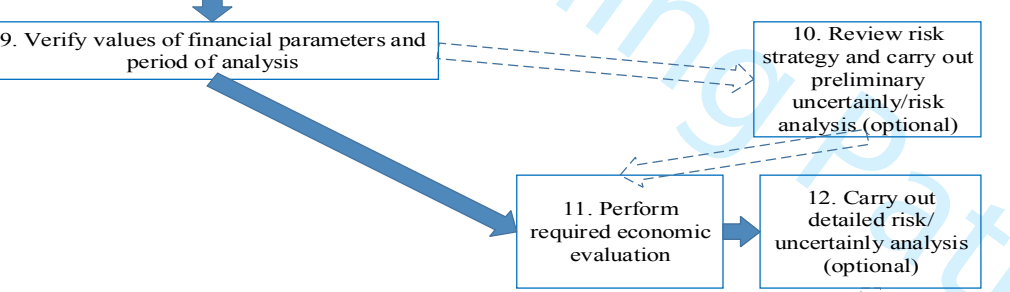

Figure 2: LCC methodology flow diagram (Langdon, 2007) 
calculations in construction projects are becoming increasingly important as awareness increases of the significance of operational and maintenance costs of buildings and the growing "value for money" trend (Gundes, 2016). In 2007, Davis Langdon Management Consulting published a common methodology for construction projects as indicated in Figure 2 below. There are 15 steps in the proposed process. The first two steps are to identify the main purpose and scope of the LCC study according to the expected outcomes. LCC calculations involve several different components incurred at various phases of a building's life-cycle. The relationship between LCC and sustainability assessment and the extent to which the latter forms an input to the LCC analysis is defined at step 3,7 and 8. The last two steps are associated with the interpretation and reporting of the outcomes and provide feedback on LCC findings into the sustainability process. Although LCC and LCA are two distinct and different processes, the LCC outputs try to provide better solutions for whole life costing, especially in energy and environmental cost consideration.

Social Life Cycle Assessment (SLCA) considers the impacts of the construction works, processes, services or products upon society or quality of life, including the aspects of health and comfort and the socio-economic as well as the cultural value of the property (British Standard 15392, 2008). The selecting and applying of indicators to the assessment depends not only on the different levels of users such as individuals (for example, the users of a building) and groups of people (for instance, students and teachers at schools) but also on the owners (state or private) of the property.

\section{Sustainable Refurbishment for Buildings}

Refurbishment issues often arise when the building's performance is not meeting the standard and quality expected. The motivation for refurbishment can be physical, functional or both requirements. The physical condition includes optimal use of existing space and an integration of innovative technology, for examples, a solar roof and recycled materials. And the functional requirement includes users' level quality comfort in the indoor environment such as heating, noise, visual, and energy consumption. The building's owners also consider refurbishing the building as an economic consideration in order to reduce maintenance cost or increase asset value (Bhuiyan et al., 2015).

The critical phases of a sustainable refurbishment project are described in Figure 3. After the aims of refurbishment based on clients' needs are defined, input information such as objectives, criteria, building condition, advantages, and limitations, are analyzed to identify alternatives for the project. Then the stakeholders select the optimal solution through a weighting process, resulting in the best solution for energy saving, comfort, healthy working environment, extension of building life cycle, economized exploitation and environmental protection. There are different ways of weighting mainly divided into monetary and nonmonetary valuation methods or in an integrated approach such as life cycle assessment thus enabling an economics analysis by life cycle costing (Ferreira et al., 2013). 


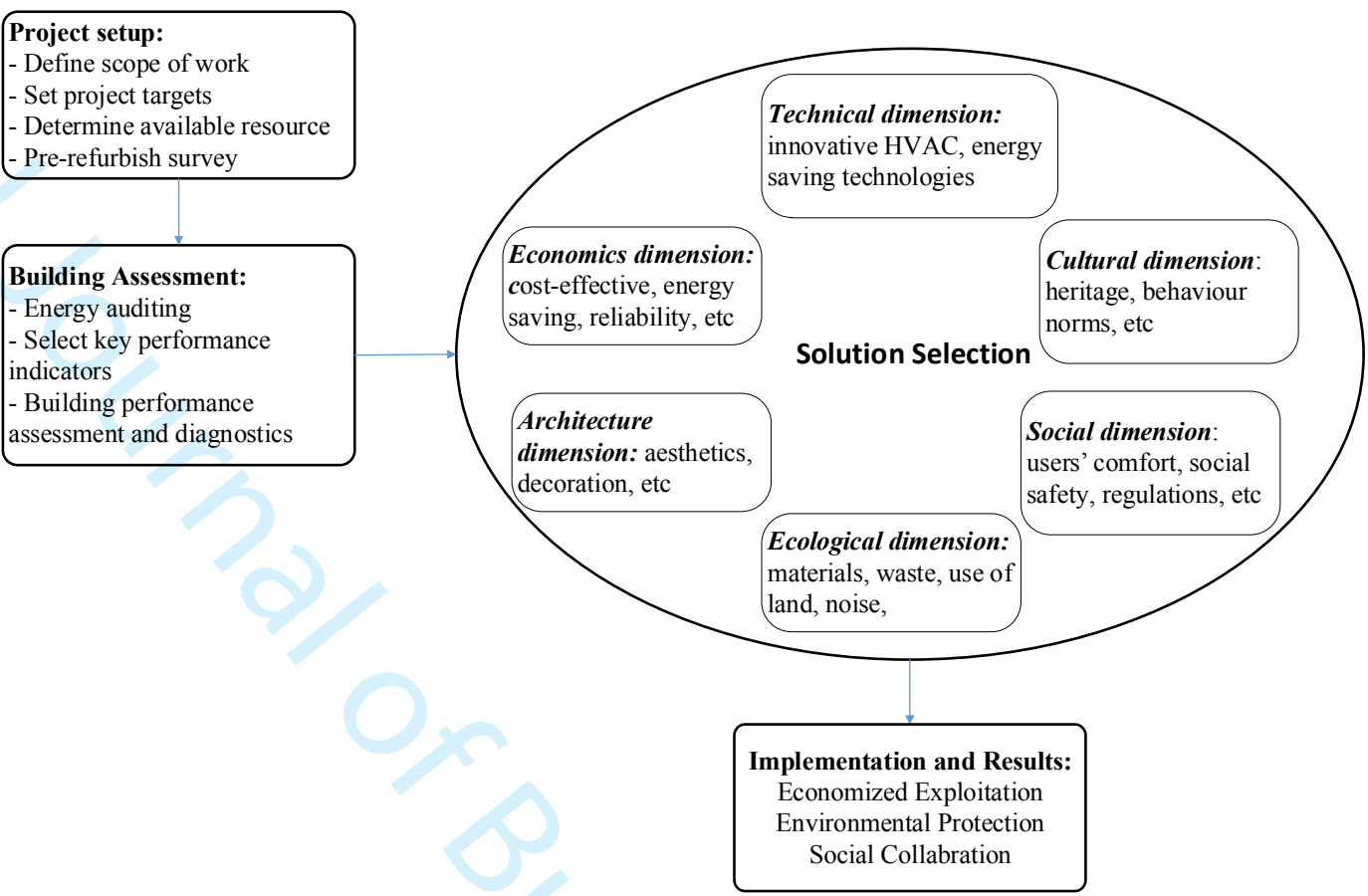

Figure 3: Key phases of sustainable refurbishment. Adapted from Zavadskas et al., (2008) and Ferreira et al., (2013)

\section{Lessons-Learned from Previous Refurbishment Projects}

This section identifies critical lessons of sustainable refurbishment from lessons learned in school building refurbishment projects in several countries. This review focuses on sustainable refurbishment projects of school buildings in the past 5 years. Based on the objectives of the paper, case studies were sought from available sources such as the journals and online public data. A literature search process with 3 steps was adopted to collect relevant literature. (1) The key words informing the search were "sustainable refurbishment", "energy retrofitting", "school building" and "educational building". The search was conducted in both Scopus and Google Scholar websites, limited to peer-review articles. The initial return to the search were 36 relevant articles. (2) Then, the second selection based on the relevance to the objectives of this study produced 11 projects. (3) The final selection was conducted considering the location of the projects resulting in six more articles being excluded. Five projects were selected, and they are summarized as follows:

- Project A: EU Project "School of the Future"- refurbishment of school buildings toward zero-emission with high-performance indoor environment (2016);

- Project B: Refurbishment in educational buildings-methodological approach for high performance integrated school refurbishment actions (2016);

- Project C: Energy retrofit of educational building: transient energy simulation, model calibration and mil-objective optimization towards nearly zero-energy performance 
(2017);

- Project D: Energy performance assessment and retrofit strategies in public school building in Rome (2014);

- Project E: Retrofitting solutions for two different occupancy levels of educational building in tropics (2016)

These lessons may provide an appropriate benchmark for best practice for school stakeholders in planning and implementing refurbishment projects. To achieve this, previous studies were critically analyzed based on the following three groups. Group (1) is to provide adequate information in deciding when and why a building required refurbishment. Group (2) is to identify important factors to consider during the refurbishment process, while Group (3) is to investigate common issues that can limit the sustainable refurbishment of school buildings.

Group 1: Refurbishment Reasons

Table 2: Refurbishment Reasons

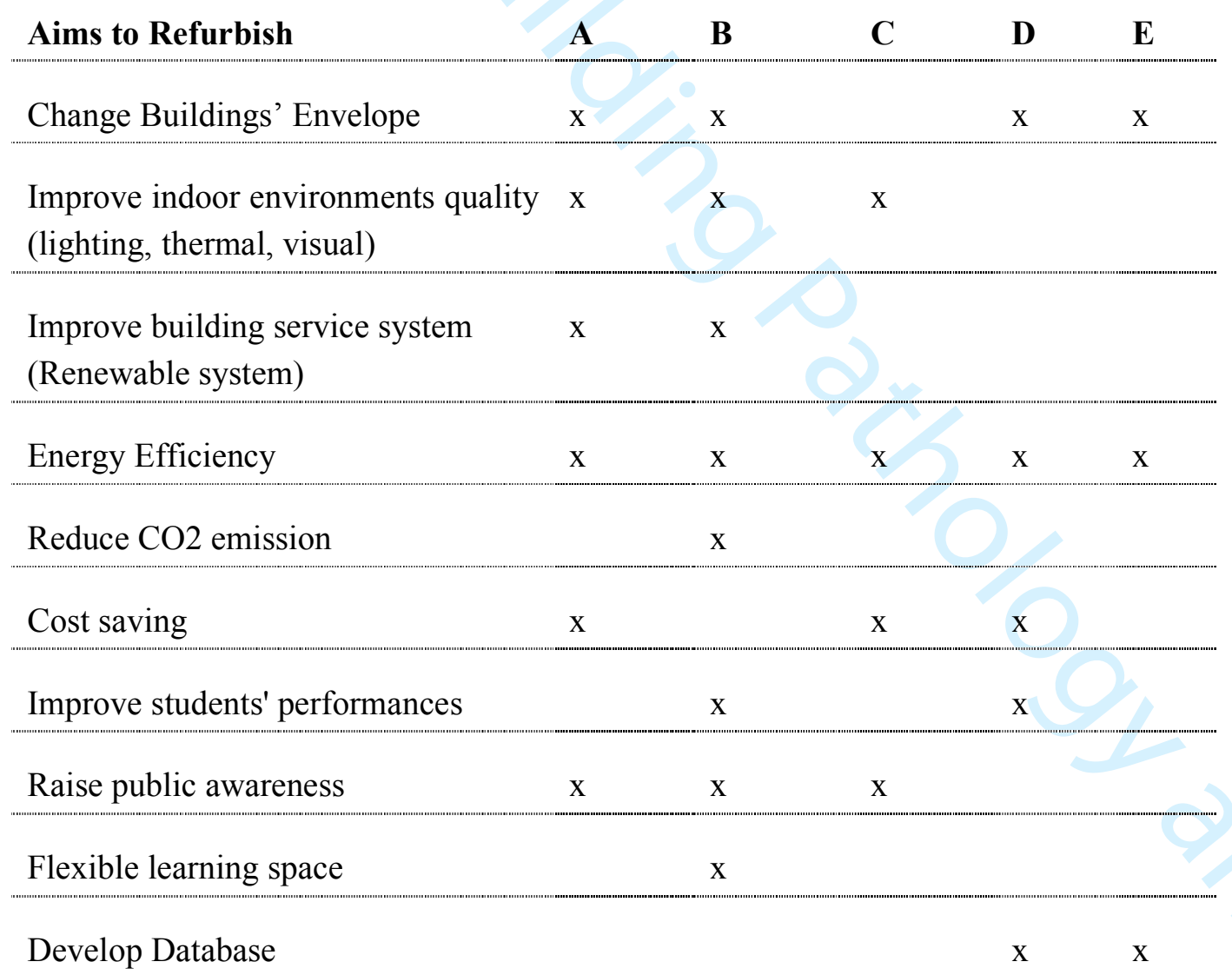

All buildings in the five projects are at an age where refurbishment is desirable. Heating systems, ventilation system, and building envelope have progressively degraded resulting in high operation and maintenance costs. Therefore, the projects target to reduce energy 
consumption and improve indoor environmental quality, moving to the use of renewable materials. Project A set solutions for zero energy schools with a reduction of total energy use and heating energy consumption by more than $75 \%$; Project $\mathrm{C}$ met the standard of nearly zero-energy performance. It also demonstrates limited additional costs needed for energy efficiency as providing reliable information, including energy saving potentials and costs to enhance the use of innovative, energy-saving retrofit concepts in public building.

Projects B and D believed that lack of comfort has negative consequences on pupils' concentration and learning. With the development of new teaching methods, learning environments have changed, requiring functional improvements to adapt learning spaces. Projects A, B and C set the goal of the sustainable refurbishment of a school building to offer a real opportunity for students, teachers, and parents to be aware of saving energy and resources and behave in a more responsible manner. Project A provides training sessions to improve users' behavior and raises their awareness of energy efficiency and the indoor environment. The advantage of this training will have an effect on other schools and the residential sector through the students' acting as communicators to their families and their peers.

Group 2: Refurbishment Process

Table 3: Refurbishment Process

\begin{tabular}{|c|c|c|c|c|c|}
\hline Refurbishment Process & $\mathbf{A}$ & B & $\mathbf{C}$ & D & $\mathbf{E}$ \\
\hline Stakeholders Engagement & $\mathrm{x}$ & $\mathrm{x}$ & & $\mathrm{x}$ & $\mathrm{x}$ \\
\hline Building Analysis & $\mathrm{x}$ & $\mathrm{x}$ & $\mathrm{x}$ & $\mathrm{x}$ & $\mathrm{x}$ \\
\hline \multicolumn{6}{|l|}{ Users' Survey } \\
\hline & $\mathrm{x}$ & $\mathrm{x}$ & $\mathrm{x}$ & & \\
\hline Simulation Program & & LIDER & $\mathrm{ML}+\mathrm{EP}$ & & \\
\hline Data Collection System & SEKS & & & $\mathrm{EL} / \mathrm{CM}$ & \\
\hline Building Diary & $\mathrm{x}$ & & & & $\mathrm{x}$ \\
\hline Sustainable Materials & $\mathrm{x}$ & $\mathrm{x}$ & $\mathrm{x}$ & & $\mathrm{x}$ \\
\hline
\end{tabular}

Where: SEKS: Stuttgart's Energy Control System (SEKS), using meters to measure the energy consumption of the whole school and sending the data to the Department of Energy Management daily

ML: MATLAB

EP: Energy Plus

CM: consumption metering, EL: Energy Label 
The successful projects were based on thorough and well-led consultation. Projects A and B define clearly the roles and communication between the stakeholders. In Project A, there is also an advisory group of researchers and practitioners to support schools in planning their project. Each project has a decision-making process framework where the first goal is to find optimal packages which minimize energy demand and discomfort and the second goal is to define an optimal cost refurbishment solution.

The building characteristics were identified in all projects as the first step in the refurbishment planning. Surveys of the occupants' comfort were conducted to assess their indoor environmental quality comfort. The energy efficiency measures were modelled for the refurbished buildings according to their characteristics and specific functions, focusing on the building envelope (wall and roof); alterations to windows, natural ventilation, and renewable resources. An air-source heat pump and PhotoVoltaics roof systems are considered as the most effective configuration of energy retrofit in school buildings.

In the selected refurbishment projects, data was collected from available sources such as a building diary, data from Council systems or through energy measurement. To identify priority actions, simulation software packages such as Energy Plus (Projects D and E) and LIDER (Project B) are used to simulate and estimate energy consumption for each scenario so as to assist stakeholders in the decision-making process.

\section{Group 3: Refurbishment Barriers and Challenges}

Project B states the need of data to identify the viability of refurbishment concepts for buildings in the public sector, while Project A points out the need for up-to-date building performance data. However, data acquisition is a challenge in the refurbishment field due to its sometimes -suspect reliability and validity.

Project B addresses limited budgets, the political, institutional framework conditions, and the lack of innovative and holistic concepts are considered as factors to prevent school buildings from comprehensive refurbishment. Furthermore, school building refurbishment focuses mostly on a single measure of maintenance and adaptation of the building structure, while functional changes are rarely considered in the refurbishment plan. The proposed methodology in Project A requires expertise in both building performance simulation software and employed optimization algorithms so users may find difficulties in using the software, designing variables and simulation, and optimization parameters. Future research should be focused on developing a simplified and integrated application tool which should be user-friendly and easy to adopt. Project E points out that, in educational buildings, the different function of rooms such as lecture rooms, seminar rooms, labs, offices, and libraries, leads to density fluctuation. Therefore, stakeholders should consider the occupancy of different areas in their refurbishment plans and procedures. 


\section{The Potential of 3D Scanner and Building Information Modelling}

Building Information Modelling (BIM) is a revolutionary approach which creates a data-rich built environment. BIM is "a new approach to design, construction and facility management (FM), in which digital representation of the building process is used to facilitate the exchange and interoperability of information in digital format" (Eastman et al., 2011). BIM is introduced to take advantage of the information sharing, collaboration and coordination amongst stakeholders and should be adopted from the beginning in the refurbishment process (Martino et al., 2015; Ilter \& Ergen, 2015; Alwan, 2016). However, there has been even less research and implementation in integrating BIM in this area (McGraw Hill Construction, 2010). According to Martino et al., (2015), there are key areas to focus on when a refurbishment project is implemented: energy efficiency, structural strengthening, collecting information on completed works, quality control and so on. To do this, BIM can be used to implement sustainable building principles in refurbishment, and the contributions of BIM usage in refurbishment areas follows (Hammond et al., 2014; McGraw Hill Construction, 2010):

- using BIM as-built model to determine what level of green building certification systems (ie. LEED, GREENSTAR) can be achieved,

- presenting building performance analyses, for example, orientation, massing, envelope, and daylighting,

- performing analyses on building functions, including energy and water use, ventilation and lighting.

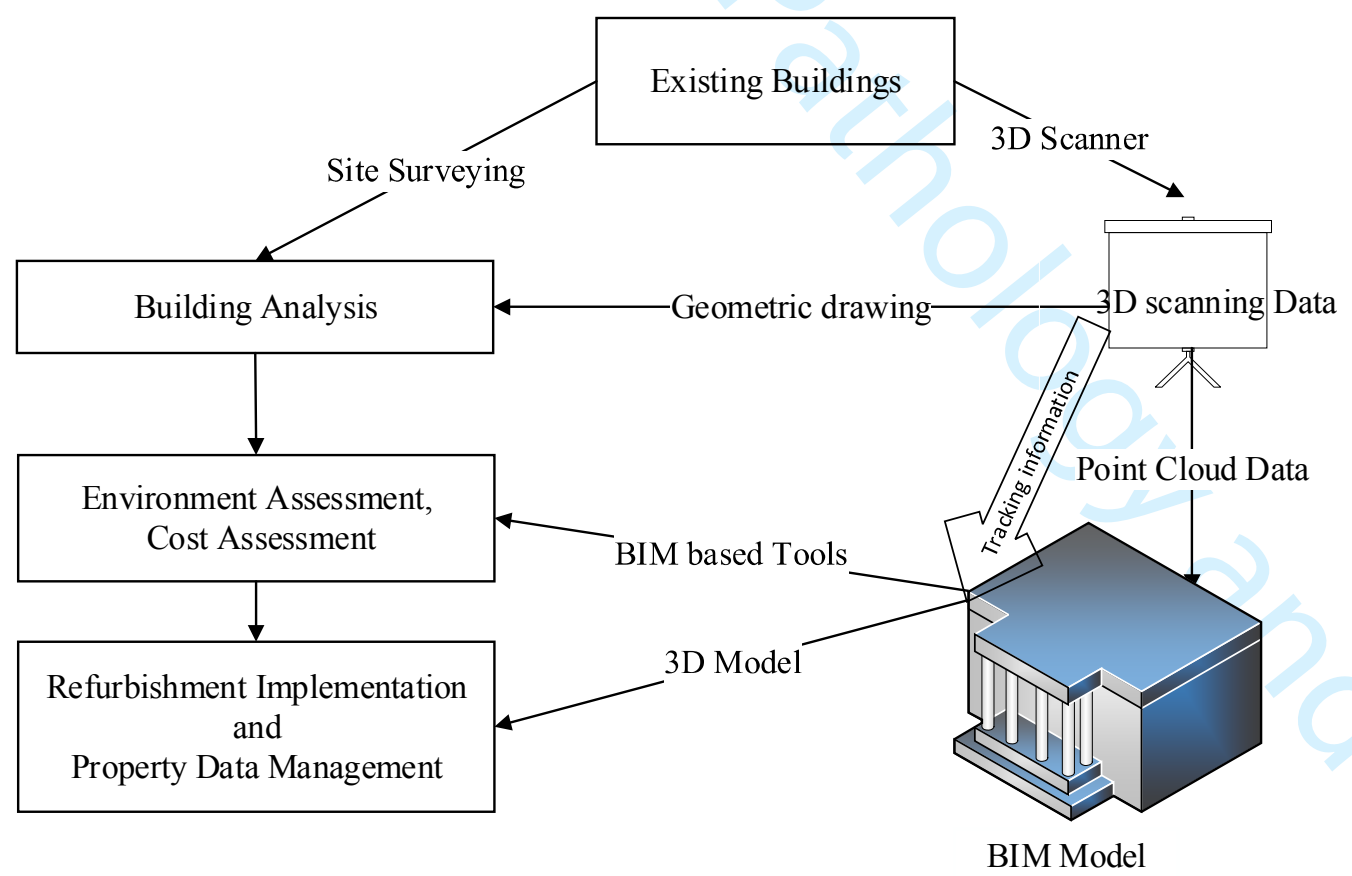

Figure 4: Proposed framework of BIM applications in the refurbishment process 
Many researchers stated that BIM offers the best method for building data management and workflow throughout a refurbishment project from the survey to design to the building site. Besides, BIM provides integrated models from different building systems, and this supports stakeholders in decision making to select the best alternative according to the lessons learned from similar projects (Roorda \& Lui, 2008). Data from a BIM model can be transferred to cost estimating software to calculate the cost of retrofits and the LCC cost of the option as well.

The main challenge involved in this refurbishment process is an investigation of the existing buildings which can provide accurate information for the decision-making process. Traditional progress tracking relies heavily on visual inspections, observational skills, and the experience of inspectors, all of which usually can be time-consuming (Brilakis et al., 2010). A 3D laser scanner can help to collect the information automatically and produces point clouds to support BIM adoption to reduce time and effort in producing as-built information with the accuracy and reliability of facility management information. Integration of 3D laser scanning and BIM has offered new possibilities for the capturing, mapping and analysis of building information (Mahdjoubi et al., 2013; Volk et al., 2014). Figure 4 shows a proposed framework for such integration in the refurbishment process.

Although there are still challenges when using BIM in retrofitting and integrating the 3D laser scan data into the BIM environment at the various stages of building surveying, inspection, and monitoring, some benefits of the integration are demonstrated from the literature, and the gap may serve as a starting point for further research.

\section{Sustainable Refurbishment Process for School Buildings}

School buildings have some characteristics which affect the refurbishment works. Baker and Peter (1963) point out that the occupancy of schools is made up of young people and different zones in multi-purpose educational buildings may cause some difficulties in carrying out maintenance and refurbishment works. In each school building, there are different functional areas or zones such as classrooms, study rooms, offices, canteens, libraries, laboratories, sports centre, sanitary facilities and playground which have different occupancy and hours of use leading to different energy consumption levels. Furthermore, literature data shows energy costs are the most significant expense in schools' running costs, except for salaries of teachers and staff. In general, space heating (47\%), lighting (14\%), cooling (10\%), ventilation (9\%) and water heating (7\%) account for $87 \%$ of energy consumption (Dias Pereira et al., 2014). Therefore, most refurbishment projects tend towards energy retrofitting with renewable system and environmental materials that could reduce energy consumption and operational cost.

One other cause of difficulty is the various levels of schools'stakeholders leading to difficulties in a collaboration which might prevent them from planning a proper sustainable refurbishment strategy for their schools (Abidin et al., 2010). The key schools' stakeholders 
in refurbishment planning and implementation usually include the school board, authorities or the local community, external planning consultants and project managers. Most of schools have to rely heavily on external planning consultants and project managers to plan and implement the refurbishment projects (Controller and Auditor General, 2017). Although a constrained budget for state schools will always exist, governments and schools try to enhance the sustainable built environment in schools to provide a high-quality indoor environment and exterior layout which can foster the creation of an atmosphere conducive to learning.

To prepare a sustainable refurbishment strategy for school building, schools' stakeholders should have a clear understanding of their roles and responsibilities to adopt a holistic approach and define a refurbishment plan based on their demand. The refurbishment plan needs to embrace sustainability from the early design phase such as a LEED, BREAM, and Green Star Certification target and the scheme should be led by the Government as a national sustainable development strategy. Collaboration between stakeholders is a key factor that enhance the sustainable refurbishment plan as shown in Figure 5.

As depicted in Figure 5, in the planning phase, the Authorities, for example, the Ministry of Education (the MOE), set the rules and policy and provide funding based on the schools' refurbishment plan. The school board has to prepare the refurbishment plans based on the school's needs and wants and the other inputs. Considering sustainable development, the school board may engage external planning consultants to help them balance cost-effective actions and environmental impacts of the refurbishment plans and social requirements.

The BIM model, as an innovation of the process, can support the decision-making process more accurately and quickly by providing BIM-based tools for the environment and economic assessment. However, it requires Planning Consultants and Project Managers with experience in using and collaborating with 3D models. The model will help to store data of refurbishment projects, but how to use the data effectively raises a question for schools.

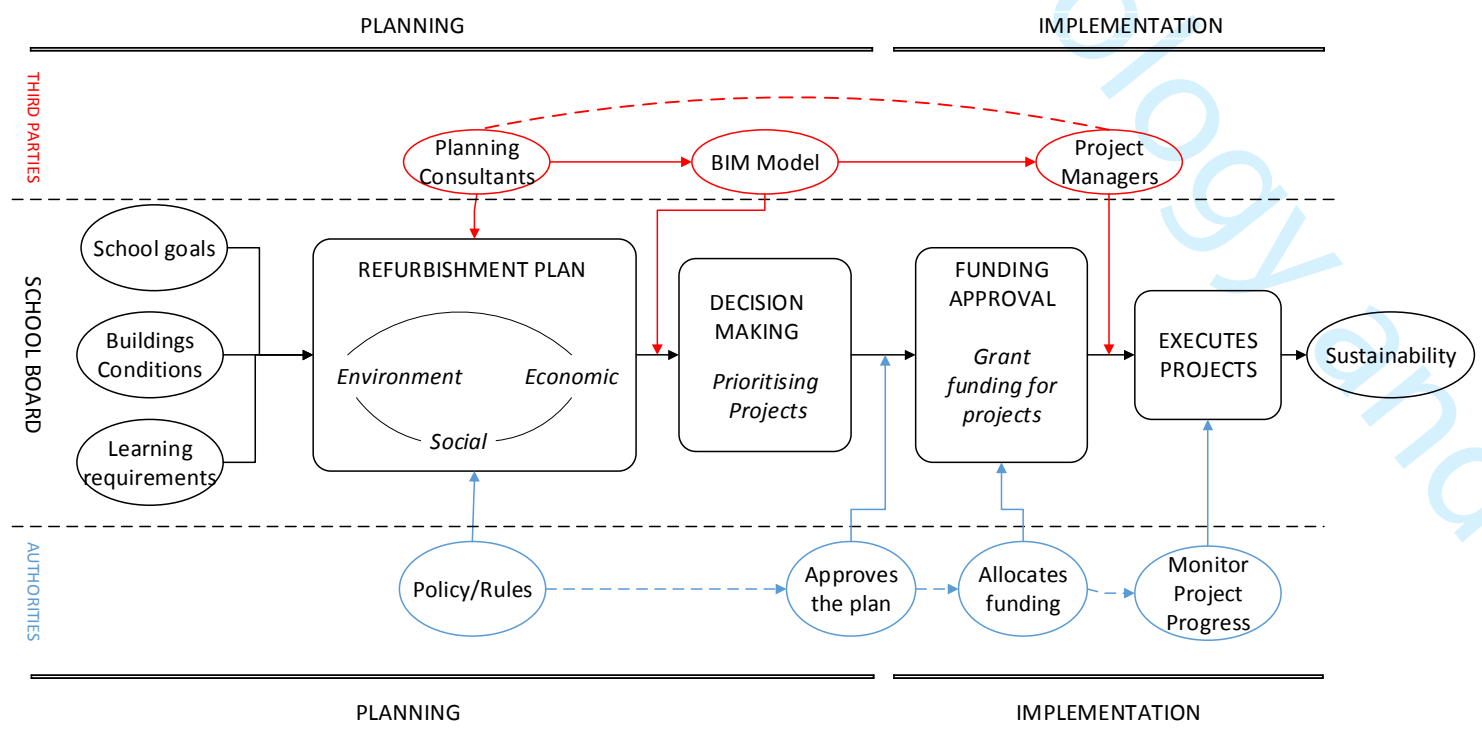


Figure 5 : Sustainable refurbishment process for school buildings

\section{Discussion}

According to the literature and lessons discussed above, recommendations toward sustainable refurbishment of school buildings are defined. To prepare a sustainable refurbishment strategy for a school building, schools' stakeholders should have a clear understanding of their roles and responsibilities to adopt a holistic approach and define a refurbishment plan based on the school's demand. The refurbishment plan needs to embrace sustainability from the early design phase such as a LEED, BREAM, and Green Star Certification target and the scheme should be led by the Government as a national sustainable development strategy. Potential benefits of innovative technology in the field such as 3D scanner and BIM should be introduced and encouraged to support decision makings in project planning, enhance the accuracy of tracking information, improve data management, and increase the productivity and profitability of sustainable refurbishment projects.

Schools as building owners/operators need to understand their existing situation thoroughly and learn from successful projects to identify a project's scope and its constraints and may engage with consultants to ensure the plan meet sustainability requirements. The most common reasons for any refurbishment are retrofitting of the building envelope (wall and roof); alterations to windows, natural ventilation, and renewable resources. Air-source heat pump and Photo Voltaic roof systems are considered as the most effective configuration of energy retrofit in school buildings. In terms of users' perspectives, surveys or interviews can be conducted to investigate teachers and students' comfort and demand, to ensure the quality of the indoor environment and raise their awareness of energy efficiency.

In the decision-making process, school refurbishment projects can include a single-objective or multi-objectives as targets to ensure that they meet their maintenance and refurbishment requirements. These objectives usually involve environmental, economic and social factors to reach projects' targets. Researchers recommend that integrating of the LCC and LCA methodologies can generate affordable refurbishment solutions (Kim and Park, 2016). Regarding the environmental aspect, they have the goal of clarifying and objectifying environmental performance levels achieved by buildings. The assessment is based upon scores awarded according to a set of performance criteria such as energy consumption, and indoor environmental quality. To evaluate environmental impacts of the refurbishment alternatives, LCA is commonly used (Ghose et al., 2017). From the economic perspectives, sustainable refurbishment offers a reduction of energy use; thus the lowering of investment and operating costs during the building's lifetime can lead to lower life-cycle cost. Life-cycle cost analysis (LCC) is used to calculate the initial investments and the future operation and maintenance costs of retrofit alternatives during a specified period of time.

During the implementation phase, work schedules should be developed from the outset in the right order and to ensure that they will meet the planned completion date. Furthermore, the 
schools and contractors should consider the school term period and teaching schedules to prevent school activities from any interruption and downtime due to construction activities. If the contractors cannot deliver a maintenance and/or refurbishment project during the school break or before/after school activities, they should ensure that light, water and other services for the existing school will not be disturbed and conduct a site safe-site workshop and training with school workers and students. At each stage, the progress should be monitored and controlled in terms of time and cost, especially if the scope is changed, such as the school's budget (Steven \& Shephearrd, 2009). Furthermore, building performance should be recorded as school maintenance data in an efficient manner because this refurbishment will not be the last project in the service life of the school. Therefore, as-built data including drawings and specifications of the refurbishment project should be kept for reference during future activities.

\section{Conclusion}

The presented study should be considered as a contribution to the challenge of sustainable refurbishment for school buildings. Regarding sustainability of school buildings, while environmental impacts can be assessed by LCA tools, and the life-cycle cost of the projects can be calculated by LCC analysis, the social benchmarking and assessment methods should not be neglected in further research. When projects set the goal of the sustainable refurbishment of a school building, they will offer a real opportunity for students, teachers, and parents to be aware of saving energy and resources and behave more responsibly. The advantage is to improve users' behavior and raise their awareness of energy efficiency and their indoor environment, and then the students act as communicators to their families and their peers who might be convinced to pay more tax for sustainable development.

Further steps are needed for the simplifying of the decision-making process to a statistical benchmark on a national level, providing a database of options and solutions for different school building levels and different-sized schools. This systematic approach to sustainable development strategies needs an extensive collaboration of stakeholders to collect experiences from similar projects and a better data management system which can provide accurate information. In this regard, 3D laser scanning and BIM can benefit many projects; they offer the best method for building data management and workflow throughout a refurbishment project from the survey stage to design, and to the building site.

\section{REFERENCES}

Abidin, Z., Akasah, B., Amirudin, R. Bin, Universiti, K., Tun, T., Onn, H., .. Bahru, J. (2010). Maintenance management process model for school buildings: An application of IDEF modeling methodology. Development, (i), 1-6.

Ali, A. ., Kamaruzzaman, N. ., \& Salleh, H. (2009). The characteristics of refurbishment projects in Malaysia. Facilities, 27(1/2), 56-65. 
Ali, A. ., Noordin, N., \& Rahmat, I. (2005). The Design process of building refurbishment on project performance. Built Environment Journal, Vol. 2, No(October 2005), 1-7.

Alwan, Z. (2016). BIM performance framework for the maintenance and refurbishment of housing stock. Structural Survey, 34(3), 242-255. https://doi.org/10.1108/SS-03-20150018

Baker, J., \& Peter, J. (1963). School Maintenance and Operation. The Interstate Printers and Publishers Inc, Danville, IL.

Bhuiyan, S. ., Jones, K., \& Wanigarathna, N. (2015). an Approach To Sustainable Refurbishment of Existing Building. In 31st Annual ARCOM Conference (pp. 10931102). Retrieved from http://www.arcom.ac.uk/docs/proceedings/2bdf2ceb7a32e4b6e197c75ce335bd3c.pdf

Bourdeau, L. (1999). Sustainable development and the future of construction: a comparison of visions from various countries. Building Research \& Information, 27(6), 354-366.

Brilakis, I., Lourakis, M., Sacks, R., Savarese, S., Christodoulou, S., Teizer, J., \& Makhmalbaf, A. (2010). Toward automated generation of parametric BIMs based on hybrid video and laser scanning data. Advanced Engineering Informatics, 24(4), 456465 .

Bristish Standard 15643-1. (2010). Sustainability of construction works — assessment of buildings Part 1: general framework.

British Standard 15392. (2008). Sustainability in building construction - General principles. British Standard.

BSI. (2015). BSI EN 16627:2015 - Sustainability of construction works - Assessment of economic performance of buildings - Calculation methods.

Chong, W. K., Kumar, S., Haas, C. T., Beheiry, S. M., Coplen, L., \& Oey, M. (2009). Understanding and Interpreting Baseline Perceptions of Sustainability in Construction among Civil Engineers in the United States. Journal of Management in Engineering, 25(3), 143-154.

Controller and Auditor General. (2017). Managing the school property portfolio.

Dias Pereira, L., Raimondo, D., Corgnati, S. P., \& Gameiro Da Silva, M. (2014). Energy consumption in schools - A review paper. Renewable and Sustainable Energy Reviews, 40, 911-922. 
Eastman, C., Teichlz, P., Sacks, R., \& Liston, K. (2011). BIM handbook: A guide to BIM for Owners, Managers, Designers, Engineers, and Contractors. John Wiley \$ Son.

Ferreira, J., Pinheiro, M. D., \& Brito, J. de. (2013). Refurbishment decision support tools review-Energy and life cycle as key aspects to sustainable refurbishment projects. Energy Policy, 62, 1453-1460.

Ghose, A., McLaren, S. J., Dowdell, D., \& Phipps, R. (2017). Environmental assessment of deep energy refurbishment for energy efficiency-case study of an office building in New Zealand. Building and Environment, 117, 274-287.

Gundes, S. (2016). The Use of Life Cycle Techniques in the Assessment of, 216(October 2015), 916-922. https://doi.org/10.1016/j.sbspro.2015.12.088

Hammond, R., Nawari, N. ., \& Walters, B. (2014). BIM in sustainable design: strategies for retrofitting/renovation". In International Conference on Computing in Civil and Building Engineering. Orlando, Florida.

Herczeg, M., McKinnon, D., Milios, L., Bakas, I., Klaassens, E., Svatikova, K., \& Widerberg, O. (2014). Resource efficiency in the building sector, (May), 1-128.

Ilter, D., \& Ergen, E. (2015). BIM for building refurbishment and maintenance : current status and research directions. Structural Survey, 33(3), 228-256.

Kim, K. P., \& Park, K. (2016). Exploring capabilities of BIM tools for housing refurbishment in the UK. Journal of KIBIM, Vol.6, No., 9-17.

Langdon, D. (2007). Life Cycle Costing (LCC) as a contribution to sustainable construction: a common methodology, (May 2007)

Mahdjoubi, L., Moobela, C., \& Laing, R. (2013). Providing real-estate services through the integration of 3D laser scanning and building information modelling. Computers in Industry, 64(9), 1272-1281.

Martino, G., Giuda, D., Villa, V., \& Piantanida, P. (2015). BIM and energy efficient retrofitting in school buildings. Energy Procedia, 78, 1045-1050.

McGraw Hill Construction. (2010). Smart Marker Report: Green BIM: how BIM is contributing to green building design and construction.

Meeus, L. (2012). How to refurbish all buildings by 2050. https://doi.org/10.2870/41596

Mickaityte, A., Zavadskas, E. K., Kaklauskas, A., \& Tupenaite, L. (2008). The concept 
model of sustainable buildings refurbishment. International Journal of Strategic

Property Management, 12(1), 53-68.

Orsterreicher, D., \& Geissler, S. (2016). Refurbishment in educational buildings methodological approach for high performance integrated school refurbishment actions. Energy Procedia, 96(October), 375-385.

Quah, L. K. (1988). An evaluation of the risks in estimating and tendering for refurbishment. Retrieved from http://ethos.bl.uk/OrderDetails.do?uin=uk.bl.ethos.424803

Roorda, D., \& Lui, M. (2008). Implementation of BIM on the renovation of the art gallary of Alberta in Edmonton. In 18th Analysis and Computation Specially Conference.

Shah, S. (2012). Sustainable refurbishment. Sustainable Refurbishment. https://doi.org/10.1002/9781118387894

Steven, P., \& Shephearrd, E. H. C. (2009). New from old : transforming secondary schools. Report of CABE- the Government Advisor on Architecture, Urban Design and Public Space. Architecture and the Built Environment.

Trachte, S., \& De Herde, A. (2015). Sustainable refurbishment school buildings. International Energy Agency. Retrieved from https://www.ieashc.org/data/sites/1/publications/subt.D.School Renovation.022015.pdf

USGBC. (2005). Building and climate change. Retrieved from https://www.usgbc.org/Docs/Archive/General/Docs18496.pdf.

Volk, R., Stengel, J., \& Schultmann, F. (2014). Building Information Modeling (BIM) for existing buildings - Literature review and future needs. Automation in Construction, 38 , $109-127$.

Vollenbroek, F. A. (2002). Sustainable development and the challenge of innovation. Journal of Cleaner Production, 10(3), 215-223.

Zamagni, A. (2012). Life cycle sustainability assessment. The International Journal of Life Cycle Assessment, 17(4), 373-376. 


\section{Sustainable Refurbishment for School Buildings: A literature Review}

Author(s') Response to Reviewers Report

Manuscript No: IJBPA-01-2018-0009

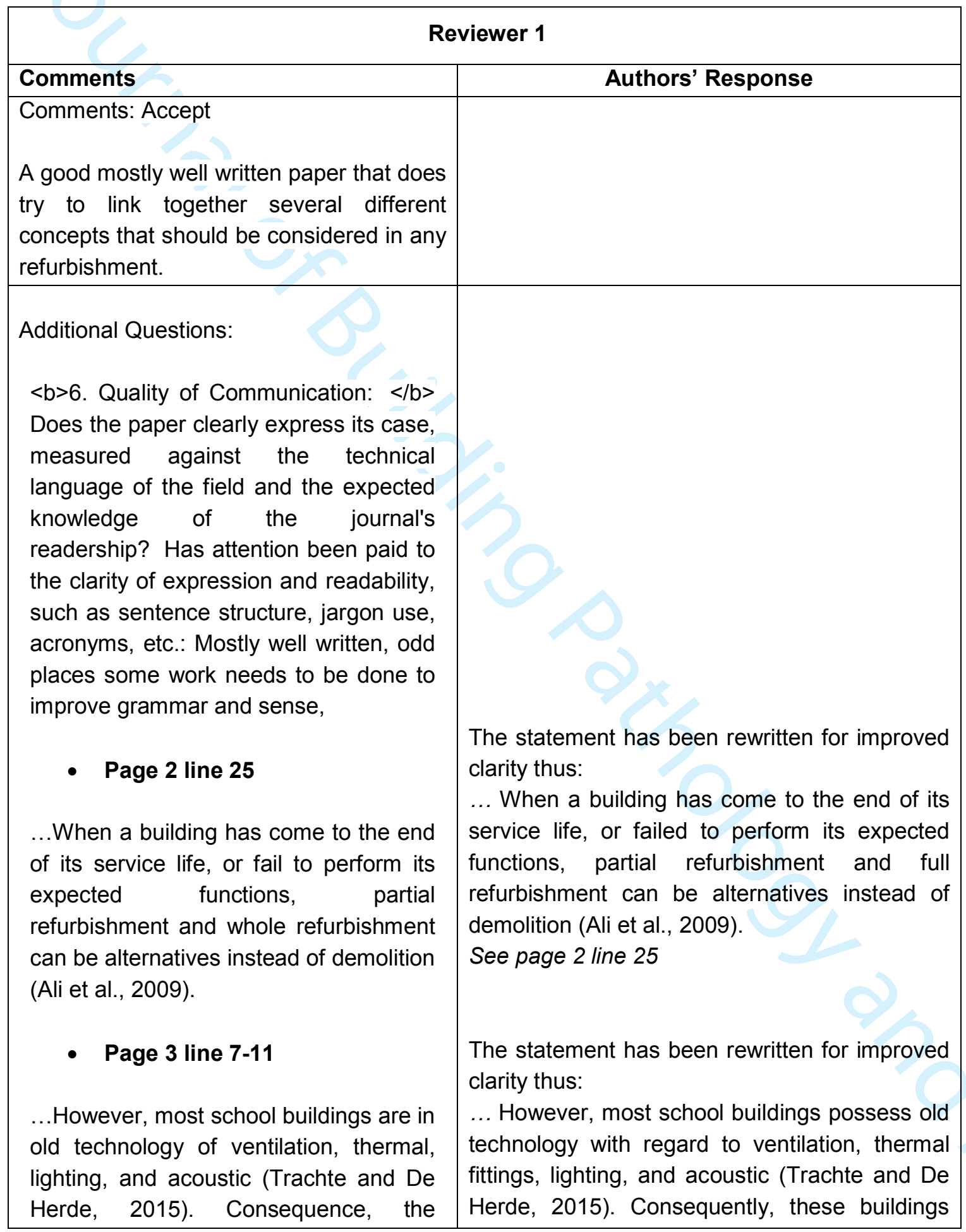


buildings are operating in high water and electricity consumption, high $\mathrm{CO} 2$ emission and uncomfortable of light and noise.

\section{- Page 3 line 36}

...The construction diversity causes more complicated to define sustainability in the industry

- Page 3 line 48 abbreviation used without first using full name;

The International Council for Research and Innovation in Building and Construction (CIB) expected that SC will lead to healthier built environment and ecological systems, energy conservation, better health and comfort of users, waste reduction, resource saving, better service life prediction and new technologies, systems for renovating and retrofitting (Bourdeau, 1999).

- Page 10 line 41 needs some work;

...All buildings in the five projects are at the age of refurbishment. Heating systems, ventilation system, and building envelope are progressively degraded resulting in high operation and maintenance costs.

- Table 3 "sustainable" spelt wrongly. are operating with high water and electricity consumption levels, high $\mathrm{CO} 2$ emissions and uncomfortably poor light and noise considerations.

See page 3 line 7-12

The statement has been rewritten for improved clarity thus:

... Construction diversity makes it complicated to define sustainability in the industry.

See page 3 line 37

The statement has been rewritten for improved clarity thus:

... The International Council for Research and Innovation in Building and Construction (CIB) expected that sustainable construction will lead to healthier built environment and ecological systems, energy conservation, better health and comfort for users, waste reduction, resource saving, better service life prediction, and new technologies, and systems for renovating and retrofitting (Bourdeau, 1999).

See page 3 line 49

The statement has been rewritten for improved clarity thus:

...All buildings in the five projects are at an age where refurbishment is desirable. Heating systems, ventilation system, and building envelope have progressively degraded resulting in high operation and maintenance costs.

See page 10 line $54-56$

The word has been corrected. 


\begin{tabular}{|c|c|}
\hline \multicolumn{2}{|c|}{ Reviewer 2} \\
\hline Comments & Authors' Response \\
\hline Comments: Major Revision & \\
\hline $\begin{array}{l}\text { Additional Questions: } \\
<\mathrm{b}>1 \text {. Originality: </b> Does the paper } \\
\text { contain new and significant information } \\
\text { adequate to justify publication? } \\
\text { Unfortunately, the paper does not yet } \\
\text { appear to contain adequate new and } \\
\text { significant information to justify } \\
\text { publication. }\end{array}$ & $\begin{array}{l}\text { This paper's findings include: } \\
\text { - a comprehensive literature review of } \\
\text { sustainability assessment and } \\
\text { sustainable refurbishment of existing } \\
\text { buildings, } \\
\text { - } \\
\text { premparisons with, and lessons from } \\
\text { refurbishment projects, } \\
\text { identification and discussion of current } \\
\text { trends and research gaps in this area } \\
\text { that would benefit from the application } \\
\text { of advanced technology such as 3D } \\
\text { laser scanning and Building Information } \\
\text { Modelling. } \\
\text { The results of this research are useful for } \\
\text { schools' decision makers and researchers } \\
\text { involved in the implementation of sustainable } \\
\text { refurbishment for school buildings and can be } \\
\text { reference for other types of buildings by } \\
\text { summarizing relevant, meaningful and } \\
\text { important quality articles and studies into one } \\
\text { complete report. It also identified gaps, and } \\
\text { contradictions in the literature that can provide } \\
\text { clues as to where future research is heading or } \\
\text { focusing. }\end{array}$ \\
\hline $\begin{array}{l}<b>2 \text {. Relationship to Literature: }</ b> \\
\text { Does the paper demonstrate an adequate } \\
\text { understanding of the relevant literature in } \\
\text { the field and cite an appropriate range of } \\
\text { literature sources? Is any significant work } \\
\text { ignored? } \\
\text { Unfortunately, the paper does not appear }\end{array}$ & To support the objectives of this study, the \\
\hline
\end{tabular}



to cite or reference a substantial body of
relevant literature sources. authors have reviewed 38 relevant literature sources such as government reports/standards, conference papers, journal articles, books, chapter of books and online materials. The search was conducted in both Scopus and Google Scholar websites, limited to peer-review articles. Although the number of references is not too much, they were identified and used properly to achieve the objectives of the literature review paper.

$<$ b >3. Methodology: </b>ls the paper's argument built on an appropriate base of theory, concepts, or other ideas? Has the research or equivalent intellectual work on which the paper is based been well designed? Are the methods employed appropriate?

The paper does not appear to have a Methodology section, although its Abstract mentions a literature review of sustainability assessment of buildings. Unfortunately, the paper does not appear to adequately describe if and/or how it undertook a critical review of substantial relevant literature. It does not appear to describe if and/or how it critically reviewed secondary literature sources in order to generate primary data that make a contribution to theory, concepts or knowledge.
The methodology of this paper is literature review. This is non-systematic review which is a critical assessment and evaluation of some but not all research studies that address lessonslearned from previous successful sustainable refurbishment projects. A non-systematic review typically includes a description of the findings of the collection of research studies, therefore, the methodology section was not separated. However, the methodology of selecting case studies/projects to analysed in the paper was presented on page 8 line 31 to page 8 line 20 thus:

"...This section identifies critical lessons of sustainable refurbishment from lessons learned in school building refurbishment projects in several countries. This review focuses on sustainable refurbishment projects of school buildings in the past 5 years. Based on the objectives of the paper, case studies were sought from available sources such as the journals and online public data. A literature search process with 3 steps was adopted to collect relevant literature. (1) The key words informing the search were "sustainable refurbishment", "energy retrofitting", "school building" and "educational building". The search was conducted in both Scopus and Google Scholar websites, limited to peer-review articles. The initial return to the search were 36 relevant articles. (2) Then, the second selection based on the relevance to the objectives of this study produced 11 projects. (3) The final selection was conducted considering the 


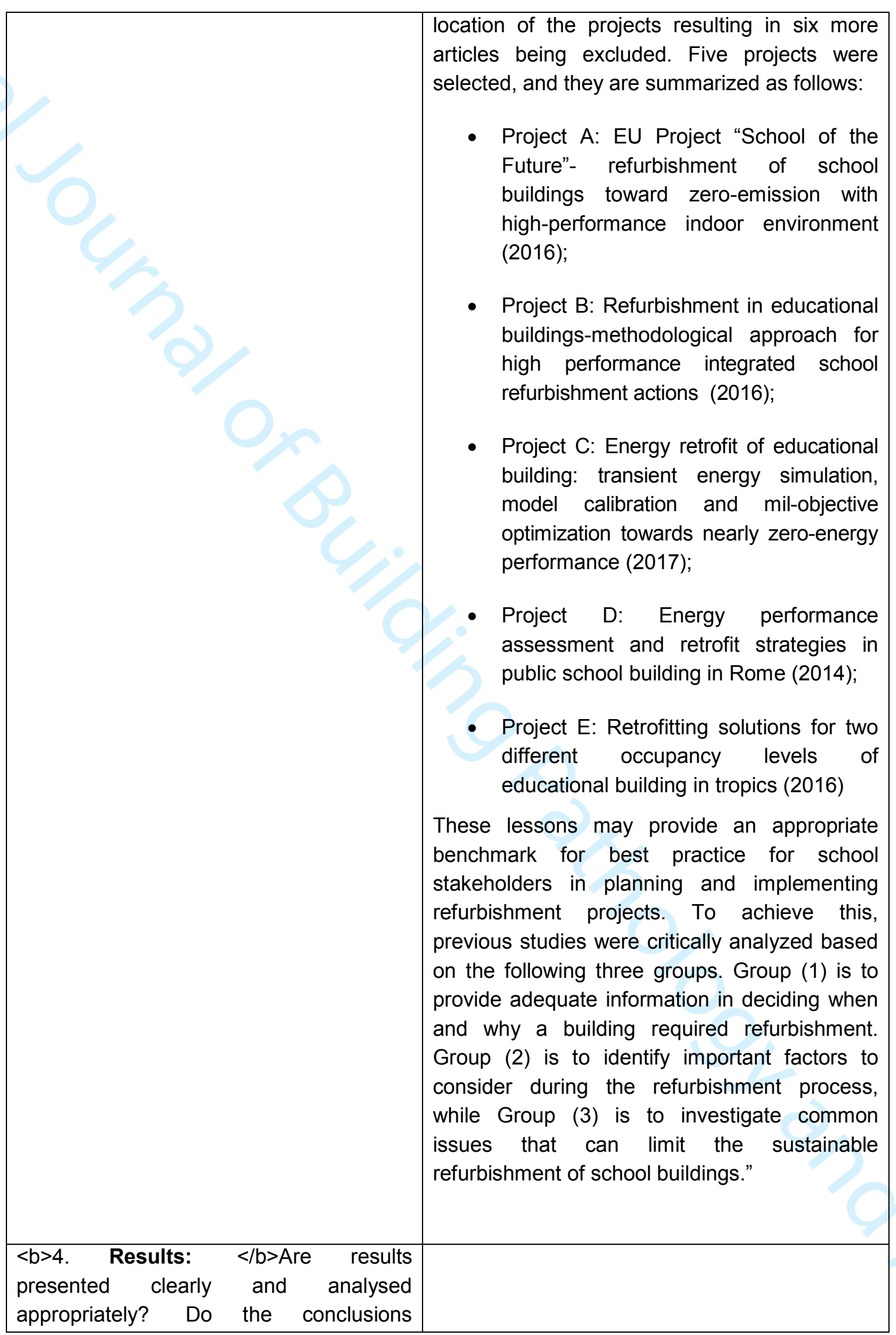




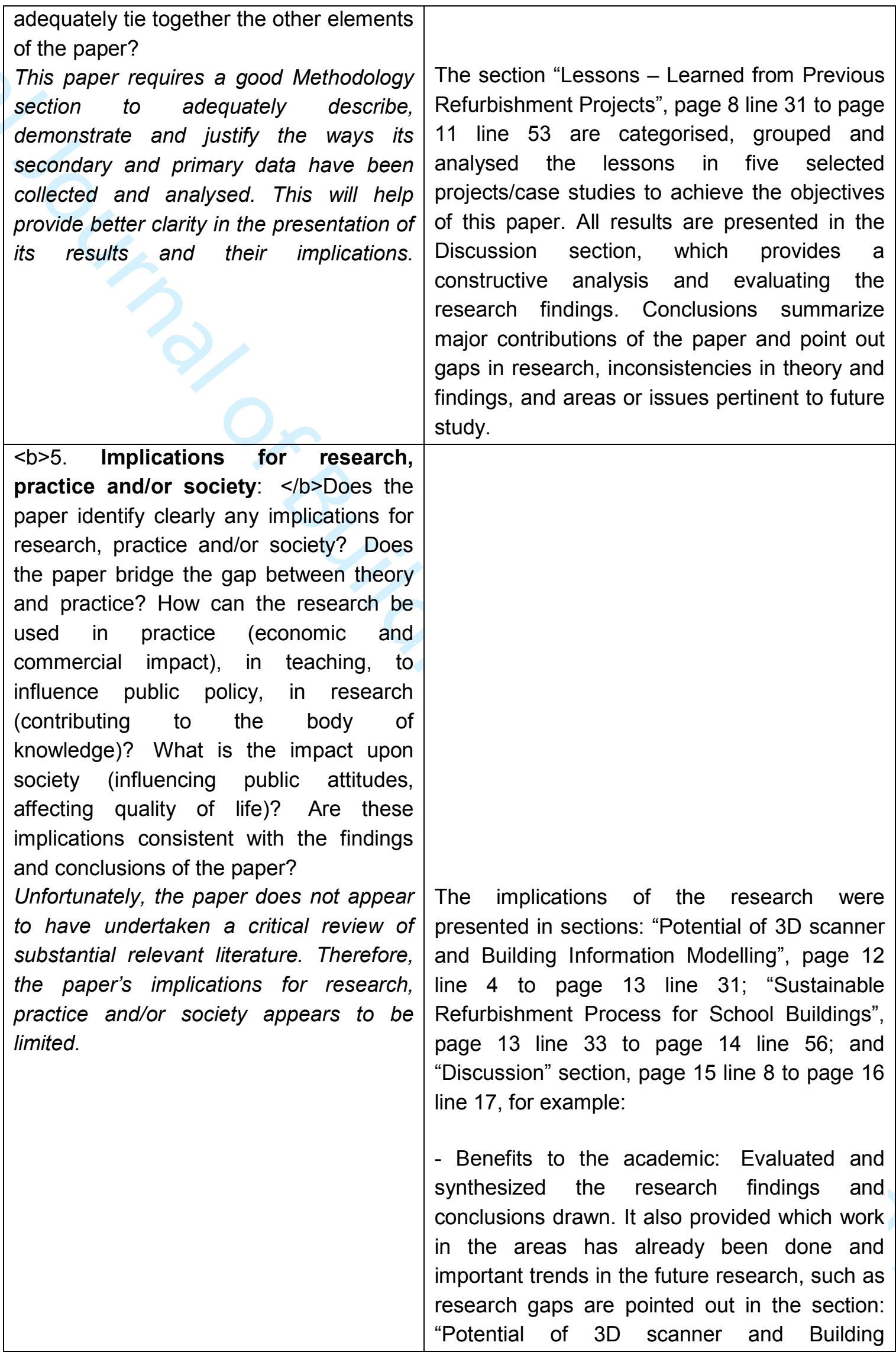




\begin{tabular}{|c|c|}
\hline & $\begin{array}{l}\text { Information Modelling". } \\
\text { - Benefits to the industry: Schools as building } \\
\text { owners/operators and schools' stakeholders } \\
\text { have lessons learned from successful projects } \\
\text { to identify a project's scope and its constraints } \\
\text { to ensure their plans meet sustainability } \\
\text { requirements. For instance, "sustainable } \\
\text { refurbishment process for school buildings" } \\
\text { which is presented in Figure } 5 \text {, page } 15 \text { will } \\
\text { help schools' stakeholder to make an informed } \\
\text { decision on refurbishment in future. } \\
\text { - Benefits to society: Raised awareness of } \\
\text { sustainable development. }\end{array}$ \\
\hline $\begin{array}{l}<b>6 \text {. Quality of Communication: }</ b> \\
\text { Does the paper clearly express its case, } \\
\text { measured against the technical language } \\
\text { of the field and the expected knowledge of } \\
\text { the journal's readership? Has attention } \\
\text { been paid to the clarity of expression and } \\
\text { readability, such as sentence structure, } \\
\text { jargon use, acronyms, etc. } \\
\text { Unfortunately, the grammar and quality of } \\
\text { communication in certain parts of the } \\
\text { paper is poor and unacceptable for } \\
\text { publication in this esteemed journal. } \\
\text { Therefore, the author(s) will need to } \\
\text { carefully proofread this paper in order to } \\
\text { identify and correct all errors and make } \\
\text { necessary modifications. }\end{array}$ & $\begin{array}{l}\text { This paper has been proofread by a } \\
\text { professional proofreading service and the } \\
\text { quality communication of the revised version is } \\
\text { significantly improved. }\end{array}$ \\
\hline
\end{tabular}

